\title{
HISTÓRICO DA COLEÇÃO DE FÓSSEIS DO INSTITUTO GEOLÓGICO
}

Criada a 27 de março de 1886, a Comissão Geográfica e Geológica (que deu origem ao Instituto Geológico) iniciou os levantamentos, estudos e pesquisas geológicos no Estado de São Paulo (então província) com os geólogos Luis Felipe Gonzaga de Campos e Francisco de Paula Oliveira, ambos formados na primeira turma da Escola de Minas de Ouro Preto, como com o próprio primeiro diretor da referida instituição, Orville Adelbert Derby, também geólogo. Mais tarde vieram integrar a mesma os geólogos Franz Eugen Hussak, Guilherme Florence e Joviano Pacheco.

"Da collecção particular da Exma. Sra. D. Bemvinda Ribeiro de Andrada é proveniente a amostra que serviu para o estudo do primeiro fossil descripto do territorio da Província, o Stereosternum tumidum (reptil fossil de Itapetininga) descripto e figurado pelo professor E. D. Cope, de Philadelphia, no Proceedings of the American Philosophical Society, de 1885" (DERBY - 1889, p.22).

Esse grupo de geocientistas estabeleceu as primeiras bases estratigráficas do Estado de São Paulo, constituídas pelas seguintes unidades: formações Faxina e Botucatu, Série Serra de São Francisco, Arenito Porto Feliz e Grupo Itapetininga (descritos em 1889), granitos Pirituba e Varejão (descritos em 1907), formações Tatuí e Corumbataí (descritas em 1916), Formação Glacial (descrita em 1917), Tilito Mandissununga e Formação Pirambóia (descritos em 1927), Grupo Taubaté (descrito em 1929) e Formação Caiuá (descrita em 1930), conforme FIGUEIRÔA (1985), p. 17 e 28. A Carta Geológica do Estado de São Paulo, contida como anexo em Washburne (1930), elaborada pela Comissão Geográfica e Geológica na escala de 1:2000000 em 1929, contemplou as seguintes unidades "litoestratigráficas" e seus respectivos períodos geológicos: Rochas metamórficas paleozóicas (Arqueano Paleozóico), Faxina (Devoniano), Glacial (Permiano), Tatuí (Permiano), Corumbataí (Permiano), Botucatu e Pirambóia (Triássico e Jurássico), Caiuá (Jurássico), Bauru (Cretáceo) e Taubaté (Terciário). Embora ocorresse a extinção da Comissão Geográfica e Geológica em 1931, os órgãos que a sucederam, bem como outras instituições, foram aperfeiçoando os co- nhecimentos estratigráficos do Estado, até que eles atingissem o grau hoje alcançado.

Como fruto do trabalho pioneiro da citada Comissão e do que se seguiu ao longo das décadas posteriores, encetado pelas instituições dela derivadas, além da contribuição de eminentes geocientistas de outros órgãos e de aficionados também de outros estados, teve origem e desenvolvimento a coleção de fósseis do Instituto Geológico, que apresenta como alguns ilustres coletores os geólogos citados no início desta exposição, além de (em ordem alfabética): Alcides Frangipani, Aníbal Alves Bastos, Armando Márcio Coimbra, Armando Wohlers, Augusto Durante, Avelino Inácio de Oliveira, Benedito Alves Ferreira, Cid Muniz Barreto, Ectore Pannuti, Elias Dolianiti, Euzébio Paulo de Oliveira, Fahad Moisés Arid, Fernando Flávio Marques de Almeida, Frederico Waldemar Lange, Jesuíno Felicíssimo Júnior, Jordano Maniero, José Epitácio Passos Guimarães, José Martin Suarez, José Setzer, Josué Camargo Mendes, Júlio César Dalponte, Kenitiro Suguio, Lewelynn Ivor Price, Mathias Gonsalves de Oliveira Roxo, Moacyr Rabello de Arruda, Octávio Barbosa, Paulo Ericksen de Oliveira, Pedro de Moura, Plínio de Lima, Próspero Cesarino Paoliello, R.W. Fern, Ruy Osório de Freitas, Sérgio Mezzalira, Setembrino Petri, Sizenando de Mendonça Chaves, Sylvio Fróes de Abreu, Theodoro Knecht, Valdemar Lefèvre e outros.

A rigor, a Comissão Geográfica e Geológica e os órgãos que a sucederam (Instituto Geográfico e Geológico e Instituto Geológico) contaram até 1981 com apenas três paleontólogos, a saber: Orville A. Derby, seguido por Joviano Pacheco e, bem mais tarde, Sérgio Mezzalira. Hoje conta com mais, o que demonstra a importância da paleontologia para o conhecimento geológico. "Foi também o geólogo Joviano Pacheco o colecionador do espécime de madeira silicificada fóssil descrita como Tietea singularis por Solms-Laubach (1913)" (MENDES - 1945, p.153). Esse exemplar foi posteriormente estudado por Derby.

Houve perda de material em virtude das várias mudanças de sede da Comissão e órgãos sucessores, bem como enriquecimento com a doação de coleção referente ao Devoniano, pela 
Divisão de Geologia e Mineralogia do DNPM, assim como referente ao Grupo Passa Dois, pelo Conselho Nacional de Petróleo.

A partir do ano de 1946, que assinala o ingresso de Sérgio Mezzalira no quadro de pessoal do Instituto Geológico (então Instituto Geográfico e Geológico), a coleção começou a ser reorganizada e grandemente aumentada face à ampla coleta de material de superfície (afloramentos) e subsuperfície (poços para captação de água subterrânea) efetuada por este, que foi o paleontólogo que mais vasculhou o território do Estado. Sua contribuição orça em mais de cinqüenta por cento do acervo, sendo 504 exemplares para um total de 1.080 animais invertebrados (incluindo-se icnofósseis), 154 para 370 animais vertebrados, 350 para 539 vegetais e 220 para 442 fósseis recentes.

Com base na descrição e identificação de exemplares da coleção foram publicados aproximadamente 76 trabalhos científicos, sendo perto de 35 de autoria de Sérgio Mezzalira e ainda cerca de 5 envolvendo bibliografias e históricos.

Atualmente, a coleção é mantida pelos paleontólogos da Seção de Paleontologia e Estratigrafia, que a enriquecem com o material obtido como fruto de suas pesquisas, servindo ainda à consulta de especialistas, além de oferecer peças para exposição no Museu Geológico. Está localizada na sede do Instituto Geológico, em São Paulo.

\section{REFERÊNCIA BIBLIOGRÁFICA}

DERBY, O.A. 1889. Retrospecto historico dos trabalhos geographicos e geologicos effectuados na Provincia de S. Paulo. Boletim da Comissão Geográfica e Geológica, São Paulo, n. 1, 26 p.

FIGUEIRÔA, S.F.M. 1985. Um século de pesquisas em geociências. Instituto Geológico, CPRN-SAA, São Paulo, 96 p.
MENDES, J.C. 1945. Esboço histórico das pesquisas paleontológicas no Brasil. Boletim da FFCL-USP, n.L, Geologia n. 2, São Paulo, p. 141-161.

WASHBURNE, C.W. 1930. Petroleum geology of the State of São Paulo - Brasil. Boletim n. 22, Comissão Geográfica e Geológica, São Paulo, 282 p. 